\section{ANNUAL CONFERENCE PREREGISTRATION}

Persons planning to attend the San Francisco Conference in June will be able to preregister by completing and mailing a form to be included in the April issue of the $A L A$ Bulletin. Pre-registration will be accepted for the full conference, June 25-July 1, 1967, only. A check for $\$ 7.50$ covering the registration fee for personal members of ALA, or $\$ 12.50$ for non-members, must accompany the application.

An official receipt will be mailed to the applicant together with a stub to be presented at the registration desk in San Francisco in exchange for the official program and other conference materials.

The deadline for pre-registration will be May 31.

무

The publication, Vocational Training for $\mathrm{Li}$ rary Technicians, a Survey of Experience to Date, by John Martinson, published October 1965, is available from the Communications Service Corporation, $1629 \mathrm{~K}$ Street N.W., Washington, D.C. 20006. The cost is $\$ 3.00$ per copy. $20 \%$ discount to libraries and education institutions.

Membership January 31, 1967

January 31, 1966
College Libraries, January 31, 1967

11,627 January 31,1966

Junior College Libraries, January 31, 1967 January 31, 1966

Rare Books Section, January 31, 1967 January 31, 1966

Subject Specialists, January 31, 1967 January 31,1966

University Libraries, January 3I, 1967 January 31, 1966
10,277

3,437

3,202

1,328

977

1,402

1,181

2,261

2,170

4,383

3,992

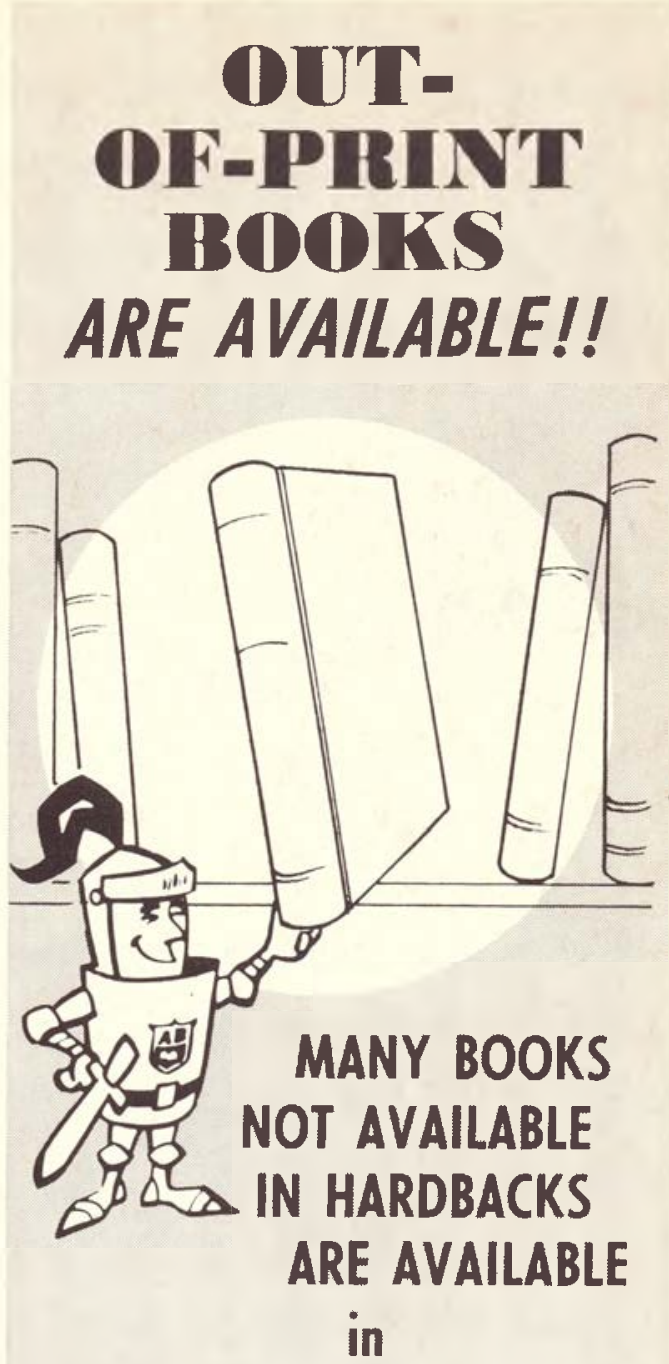

\section{LIBRARY BOUND PAPERBĀCKS}

We make library-bound hardbacks out of paperbacks - They're called ARMOR BOOKS.

Our regular catalog covers the most widely used list of more than 1500 titles for supplementary reading - all educator approved; and, if it's not in the catalog, we can supply it.

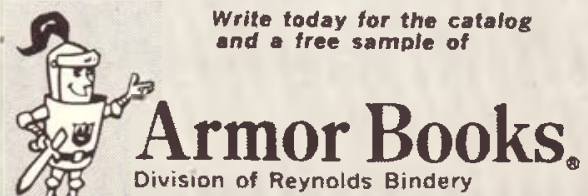

